\title{
Compactação do solo na cultura do feijoeiro. II: efeito sobre o desenvolvimento radicular e da parte aérea
}

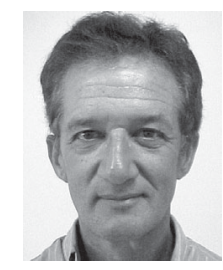

Cleber M. Guimarães ${ }^{1}$, Luís F. Stone ${ }^{2}$ \& José A. A. Moreira ${ }^{3}$

\author{
1 Embrapa Arroz e Feijão. CP 179, CEP 75375-000, Santo Antônio de Goiás, GO. Fone: (62) 533-2178, Fax: (62) 533-2100. \\ E-mail: cleber@cnpaf.embrapa.br (Foto) \\ ${ }^{2}$ Embrapa Arroz e Feijão. E-mail: stone@cnpaf.embrapa.br \\ ${ }^{3}$ Embrapa Arroz e Feijão. E-mail: jaloisio@cnpaf.embrapa.br
}

Protocolo $171-5 / 12 / 2001$

\begin{abstract}
Resumo: $O$ que se objetivou através deste trabalho, foi estudar o efeito da compactação do solo sobre o desenvolvimento radicular e da parte aérea do feijoeiro, em casa-de-vegetação da Embrapa Arroz e Feijão, em Santo Antônio de Goiás, GO, em colunas de solo acondicionadas em tubos de PVC de $40 \mathrm{~cm}$ de altura e $25 \mathrm{~cm}$ de diâmetro, nas quais foram avaliadas duas cultivares de feijoeiro, Pérola e BAT 477, nas densidades do solo de 1,0,1,2, 1,4 e 1,6 kg dm${ }^{-3}$. As densidades foram produzidas artificialmente na camada de $0-20 \mathrm{~cm}$ de profundidade, sendo o solo mantido a um potencial da água no solo entre -35 e -10 kPa. Foram avaliadas, aos 15, 30, 45, 60 e 72 dias após a emergência, a massa da matéria seca, a densidade de comprimento e a espessura radicular, a massa da matéria seca da parte aérea, a área foliar e a massa específica foliar. O aumento da compactação do solo afetou negativamente o desenvolvimento do sistema radicular e da parte aérea do feijoeiro, sendo o efeito mais expressivo a partir da densidade do solo de $1,2 \mathrm{~kg} \mathrm{dm}^{-3}$. A cultivar Pérola apresentou parte aérea e radicular mais desenvolvidas que a BAT 477, quando não havia impedimento físico no solo ao desenvolvimento radicular. A cultivar BAT 477, entretanto, caracterizou-se pela maior rusticidade, pois foi menos afetada que a Pérola, quando submetida à compactação do solo apresentando, nestas condições, maior área foliar e acúmulo de matéria seca da parte aérea.
\end{abstract}

Palavras-chave: Phaseolus vulgaris, variedades de feijão, densidade do solo, crescimento da planta

\section{Soil compaction in a bean crop. II: Effect on root and shoot development}

\begin{abstract}
This study was conducted with the objective of verifying how soil compaction affects root and shoot development of a bean crop. The experiment was carried out in a greenhouse of Embrapa Rice \& Beans, in Santo Antônio de Goiás, GO, Brazil, in soil columns packed in PVC tubes $40 \mathrm{~cm}$ high and $25 \mathrm{~cm}$ of internal diameter. The soil columns were artificially compacted to provide soil bulk densities of $1.0,1.2,1.4$ and $1.6 \mathrm{~kg} \mathrm{dm}^{-3}$ in the $0-20 \mathrm{~cm}$ soil layer. Bean varieties Pérola and BAT 477 were grown in the soil columns. The soil water potential was maintained between -35 and -10 $\mathrm{kPa}$. The evaluations were made at $15,30,45,60$, and 72 days after emergence. The root dry matter, root length density, root thickness, leaf area, shoot dry matter, and specific leaf weight were evaluated. The increase in soil compaction negatively affected root and shoot development of bean, the effect being more expressive at bulk density values higher than $1.2 \mathrm{~kg} \mathrm{dm}^{-3}$. Pérola variety showed more root and shoot development than BAT 477 when there was no physical restriction in the soil for root development. BAT 477, however, was more rustic being less affected by soil compaction and showing higher leaf area and shoot dry matter under this situation.
\end{abstract}

Key words: Phaseolus vulgaris, bean varieties, bulk density, plant growth

\section{INTRODUÇÃO}

O feijoeiro é, entre outras culturas, muito sensível à compactação do solo. No arroz de terras altas, tanto a parte subterrânea como a aérea são afetadas quando a densidade do solo é superior a 1,2 $\mathrm{Mg} \mathrm{m}^{-3}$ (Guimarães \& Moreira, 2001). Esta condição de densidade é comum nos campos de produção, principalmente naqueles sob plantio direto. A restrição à penetração radicular nas camadas compactadas é agravada quando as condições hídricas não são favoráveis, o que pode ser devido à insuficiência de pressão de turgescência radicular para vencer o impedimento mecânico do solo (Veen, 1982).

A compactação, ao limitar o crescimento radicular das plantas (Rosolem et al., 1994; Fernandez et al., 1995; Guimarães \& Moreira, 2001) compromete sua capacidade em absorver nutrientes e água (Hakansson et al., 1988; Fernandez et al., 
1995) e a própria fixação ao solo, causando debilitação e acamamento, sobretudo quando a camada de compactação é superficial. A compactação afeta a parte aérea das plantas, reduzindo a área foliar (Beemster et al., 1996) e a produtividade (Oussible et al., 1992). Compactação ocorre, em geral, em solos manejados de forma inadequada, causando grandes prejuízos, principalmente nas regiões com distribuição pluvial irregular. Em tais condições, as reservas hídricas ao alcance do limitado sistema radicular são rapidamente consumidas, podendo ocorrer severa deficiência hídrica na planta (Barton et al., 1966). Dependendo da sensibilidade das espécies e das condições ambientais, têm-se observado reduções de até $75 \%$ da produtividade, como no feijoeiro quando submetido à compactação (Orzolek, 1991). Entretanto, Oussible et al. (1992) encontraram efeitos menos drásticos no trigo cultivado em um solo franco-argiloso compactado a uma densidade de aproximadamente $1,51 \mathrm{Mg} \mathrm{m}^{-3}$, em que verificaram reduções na produtividade de grãos e na matéria seca, de $9-20 \%$ e $12-23 \%$, respectivamente.

O objetivo deste trabalho foi estudar o efeito de diferentes densidades do solo sobre o desenvolvimento do sistema radicular e da parte aérea do feijoeiro.

\section{MATERIAL E MÉTODOS}

O estudo foi realizado em casa-de-vegetação da Embrapa Arroz e Feijão, em Santo Antônio de Goiás, GO. O solo utilizado foi um Latossolo Vermelho perférrico, com as seguintes características químicas e físicas: $\mathrm{pH}\left(\mathrm{H}_{2} \mathrm{O}\right)=5,3 ; \mathrm{Ca}^{2+}=8,1 \mathrm{mmol}_{\mathrm{c}} \mathrm{dm}^{-3}$; $\mathrm{Mg}^{2+}=2,9 \mathrm{mmol}_{\mathrm{c}} \mathrm{dm}^{-3} ; \mathrm{Al}=7 \mathrm{mmol}_{\mathrm{c}} \mathrm{dm}^{-3}, \mathrm{P}=3,1 \mathrm{mg} \mathrm{dm}^{-3}$, $\mathrm{K}=84 \mathrm{mg} \mathrm{dm}^{-3}, \mathrm{Cu}=1,3 \mathrm{mg} \mathrm{dm}^{-3}, \mathrm{Zn}=1,5 \mathrm{mg} \mathrm{dm}^{-3}, \mathrm{Fe}=74 \mathrm{mg} \mathrm{dm}^{-3}$, $\mathrm{Mn}=21 \mathrm{mg} \mathrm{dm}^{-3}$, M.O. $=23 \mathrm{~g} \mathrm{dm}^{-3}$, Silte $=80 \mathrm{~g} \mathrm{~kg}^{-1}$; Areia $=$ $430 \mathrm{~g} \mathrm{~kg}^{-1}$ e Argila $=490 \mathrm{~g} \mathrm{~kg}^{-1}$, determinadas segundo metodologia apresentada em EMBRAPA (1997). O delineamento experimental foi de blocos ao acaso, com parcelas subdivididas, com três repetições. As unidades experimentais foram colunas de solo, acondicionadas em tubos de PVC de 40 $\mathrm{cm}$ de altura e $25 \mathrm{~cm}$ de diâmetro interno, nas quais foram colocadas seis sementes das cultivares de feijão Pérola ou BAT 477. Após a emergência das plântulas fez-se o desbaste, deixando-se apenas três por coluna de solo. As cultivares constituíram as parcelas e as densidades do solo, 1,0;1,2;1,4 e $1,6 \mathrm{Mg} \mathrm{m}^{-3}$, as subparcelas. As densidades do solo foram produzidas artificialmente na camada de $0-20 \mathrm{~cm}$ de profundidade, utilizando-se uma prensa hidráulica para se estabelecer as densidades de 1,4 e 1,6 $\mathrm{Mg} \mathrm{m}^{-3}$. O solo usado foi secado ao ar e passado em peneiras com malha de $2 \mathrm{~mm}$. Durante a execução do experimento, foram feitas irrigações para elevar o conteúdo de água do solo para a capacidade de campo (-10 kPa) sempre que tensiômetros instalados a $10 \mathrm{~cm}$ de profundidade sinalizavam que o potencial da água do solo estava ao redor de $-35 \mathrm{kPa}$. Determinaram-se a massa da matéria seca das raízes e da parte aérea, a massa específica foliar, a área foliar, o comprimento, a densidade de comprimento e a espessura radicular. As avaliações foram efetuadas aos 15, 30, 45, 60 e 72 dias após a emergência, sendo as variáveis radiculares avaliadas nas camadas de $0-20$ e $20-40 \mathrm{~cm}$ de profundidade e, como as amostragens eram destrutivas, estabeleceu-se um conjunto de 24 tubos (duas cultivares $\mathrm{x}$ quatro densidades do solo $x$ três repetições) para cada data de amostragem.

A área foliar foi determinada pelo medidor de área foliar marca LI-COR, modelo 320-SE e a massa específica foliar pela relação entre a massa da matéria seca das folhas e a área foliar. O comprimento radicular total nas amostras de solo foi determinado pelo método de Newman (1966) e a densidade de comprimento radicular, conforme Taylor (1986). Após essas determinações, as raízes foram levadas à estufa, com circulação forçada de ar, a $80{ }^{\circ} \mathrm{C}$, durante o período de $48 \mathrm{~h}$, para determinação da massa da matéria seca. A espessura radicular foi inferida pela relação massa da matéria seca radicular, em mg, pelo comprimento das raízes, em $\mathrm{cm}$, segundo Oussible et al. (1992). Foram ajustadas curvas para os dados obtidos em função do tempo.

\section{RESULTADOS E DISCUSSÃO}

O desenvolvimento radicular das cultivares Pérola e BAT 477 foi afetado de forma diferente pelos níveis de densidade do solo (Figuras 1 e 2). A cultivar Pérola apresentou, em relação à BAT 477, maior massa de matéria seca e maior densidade de comprimento radicular nas densidades do solo de 1,0 e $1,2 \mathrm{Mg}$ $\mathrm{m}^{-3}$, na camada de 0-20 cm (Figs. 1A, 1B, 2A e 2B). Entretanto, nas densidades de $1,4 \mathrm{e} 1,6 \mathrm{Mg} \mathrm{m}^{-3}$, o comportamento das duas cultivares foi semelhante; já na camada de $20-40 \mathrm{~cm}$, apenas nas menores densidades houve desenvolvimento do sistema radicular (Figs. 1C, 1D, 2C e 2D) tendo a cultivar BAT 477 apresentado maiores valores das variáveis radiculares em relação à Pérola, sugerindo que, embora a planta da cultivar BAT 477 não tenha sistema radicular muito desenvolvido, ele é vigoroso o suficiente para romper camadas com impedimentos físicos, tais como as observadas, geralmente, nas áreas sob plantio direto, na região dos cerrados. Esses resultados concordam com os obtidos por Meredith \& Patrick Jr. (1961) e Cintra et al. (1983) que observaram que a redução da macroporosidade do solo a valores inferiores a $0,15 \mathrm{~m}^{3} \mathrm{~m}^{-3}$, prejudicou o crescimento das raízes, e com os obtidos por Rosolem et al. (1999) que verificaram que valores de resistência do solo à penetração maiores que $1,3 \mathrm{MPa}$, reduziram o crescimento das raízes de milho. Neste trabalho, só a partir da densidade de 1,4 $\mathrm{Mg} \mathrm{m}^{-3}$, a macroporosidade apresentou valores menores que $0,15 \mathrm{~m}^{3} \mathrm{~m}^{-3}$, e a resistência do solo à penetração maior que 1,3 MPa (Stone et al., 2002). Merotto Jr. \& Mundstock (1999), em trigo, e Rosolem et al. (1994), em soja, também verificaram que a compactação do solo reduziu a massa da matéria seca das raízes. Ademais, esses últimos autores e Rosolem et al. (1999) observaram também redução no comprimento radicular.

A espessura radicular, inferida pela relação massa da matéria seca/comprimento radicular, diminuiu com o número de dias após a emergência (Fig. 3). Esta variável, na camada de 0 - 20 $\mathrm{cm}$, apresentou maiores valores para ambas as cultivares, a medida em que aumentou a compactação do solo (Figs. 3A e 3B) sendo este resultado mais expressivo para a cultivar Pérola. $\mathrm{O}$ aumento da espessura radicular com o incremento da compactação do solo também foi observado por Oussible et al. 
A.

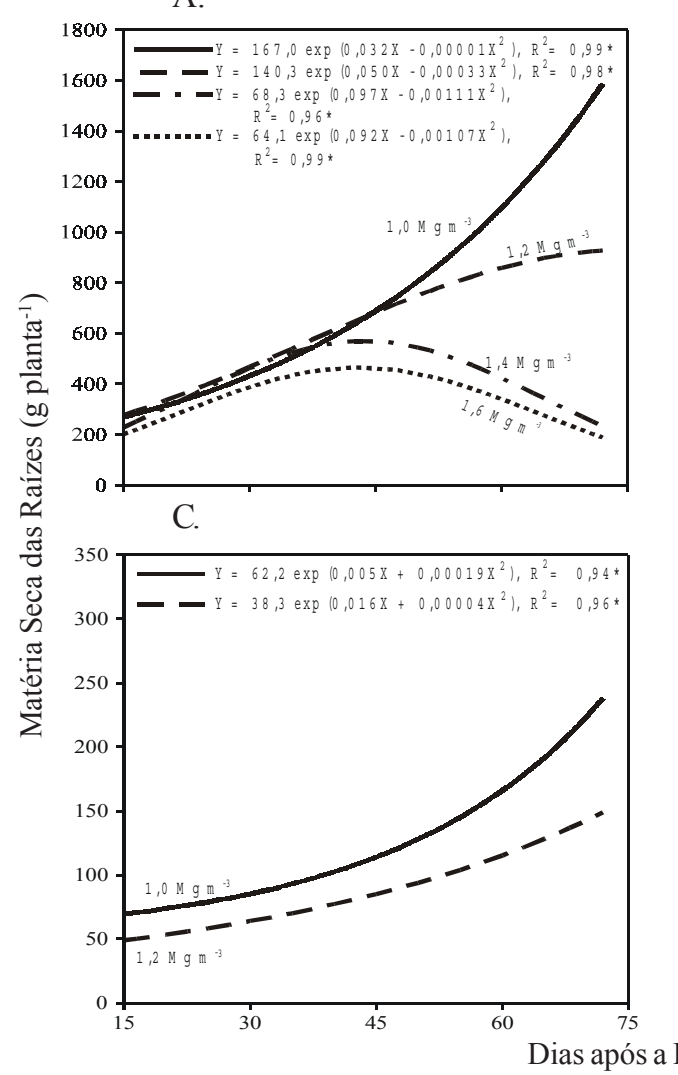

B.

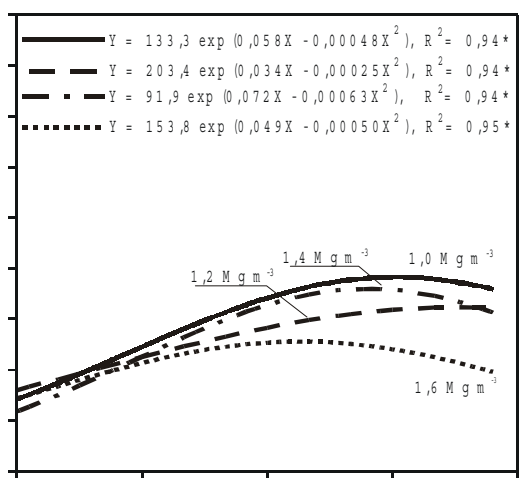

D.

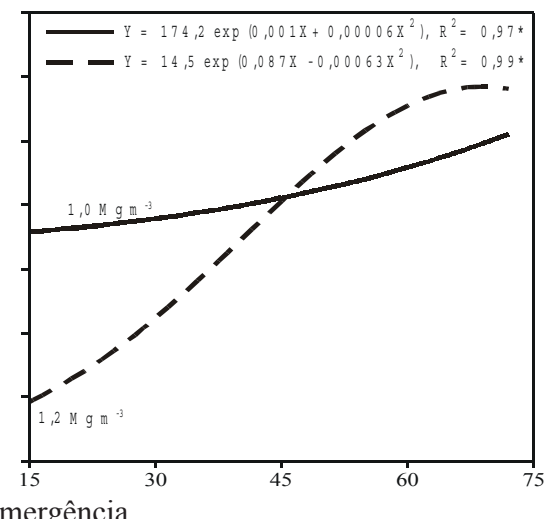

Figura 1. Massa da matéria seca das raízes das cultivares Pérola (A, C) e BAT 477 (B, D) nas camadas de solo de 0 - $20 \mathrm{~cm}$ (A, B) e 20 - $40 \mathrm{~cm}(\mathrm{C}, \mathrm{D})$ submetidas a quatro níveis de densidade do solo, na camada superficial

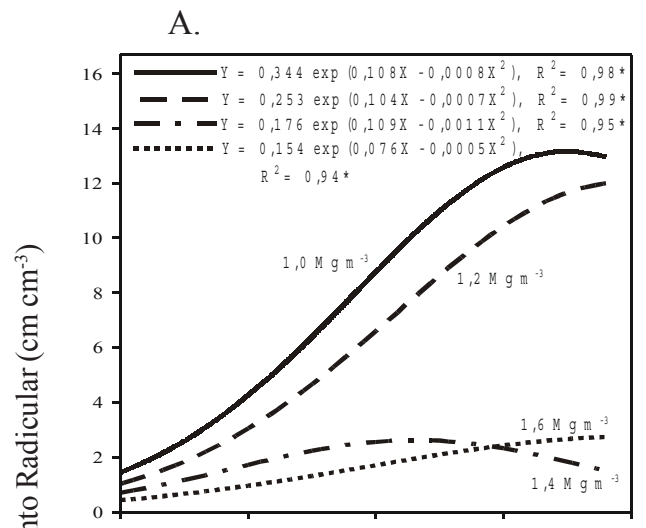

C.

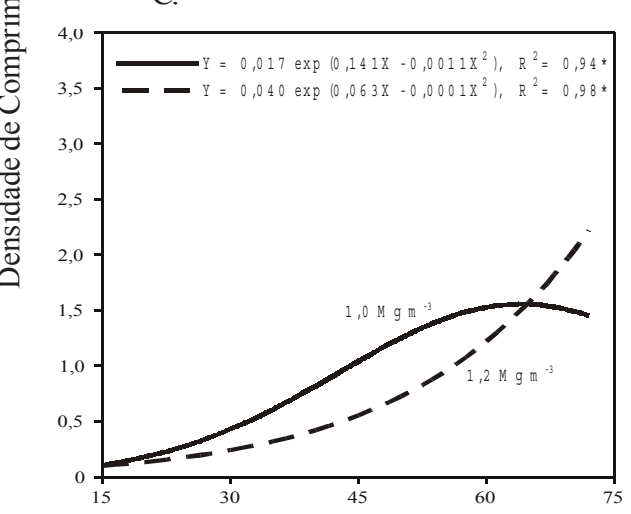

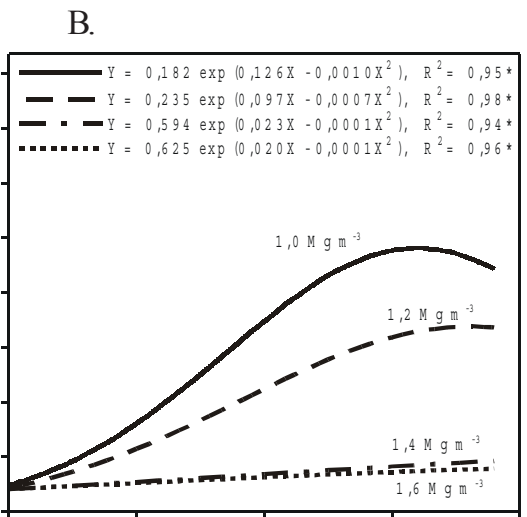

D.

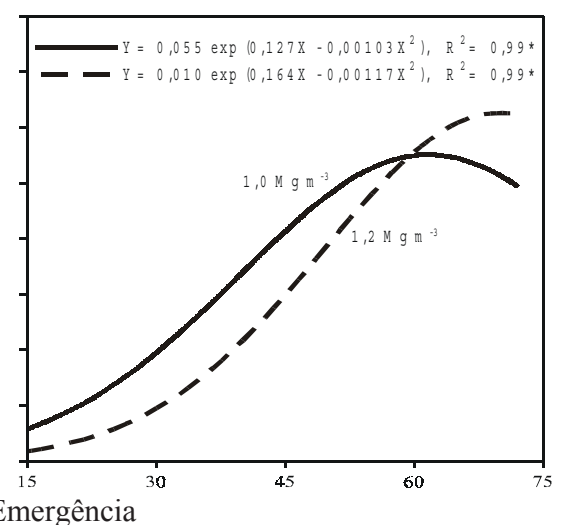

Figura 2. Densidade de comprimento radicular das cultivares Pérola (A, C) e BAT 477 (B, D) nas camadas de solo de 0 - $20 \mathrm{~cm}$ (A,

B) e 20 - $40 \mathrm{~cm}(\mathrm{C}, \mathrm{D})$ submetidas a quatro níveis de densidade do solo, na camada superficial 


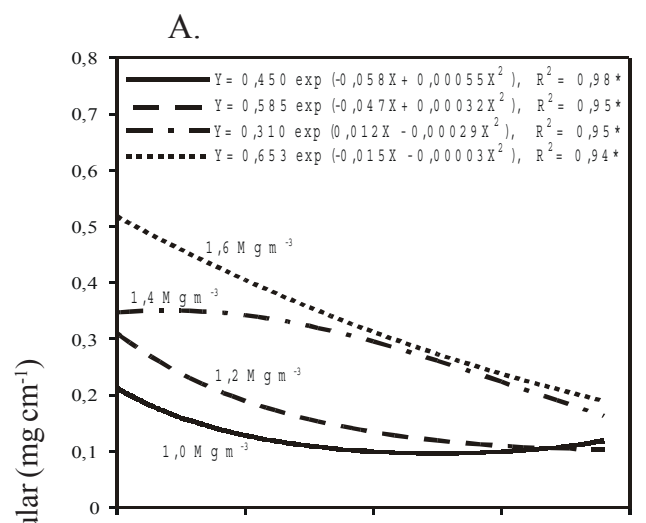

C.

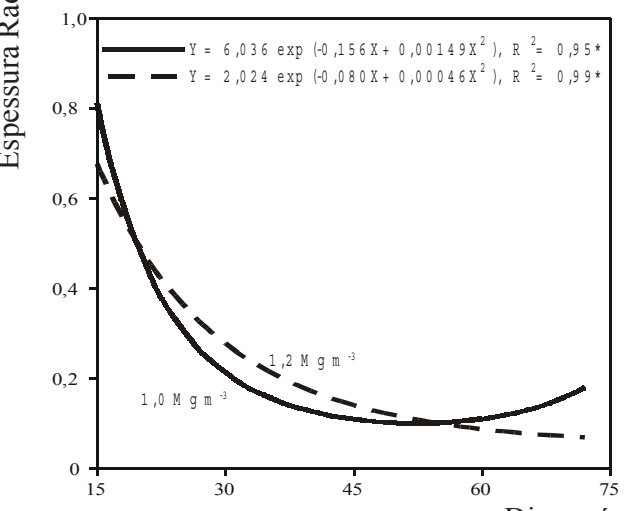

B.

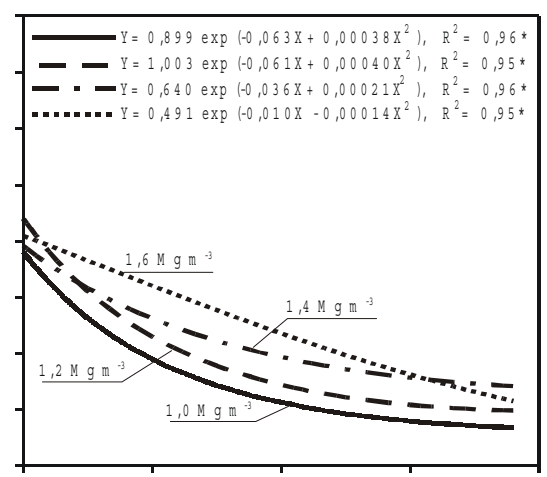

D.

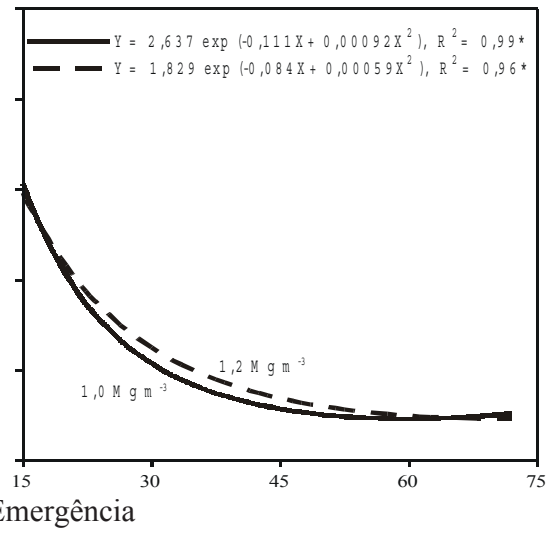

Figura 3. Espessura radicular das cultivares Pérola (A, C) e BAT 477 (B, D) nas camadas de solo de 0 - $20 \mathrm{~cm}$ (A, B) e 20 - $40 \mathrm{~cm}$ (C, D) submetidas a quatro níveis de densidade do solo, na camada superficial

A.

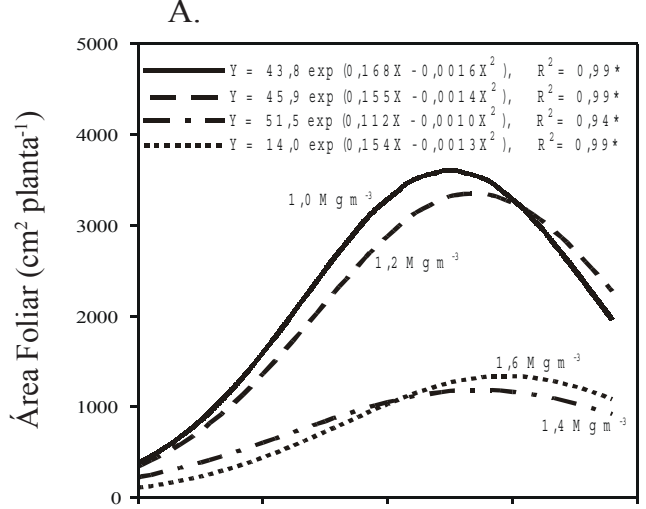

C.

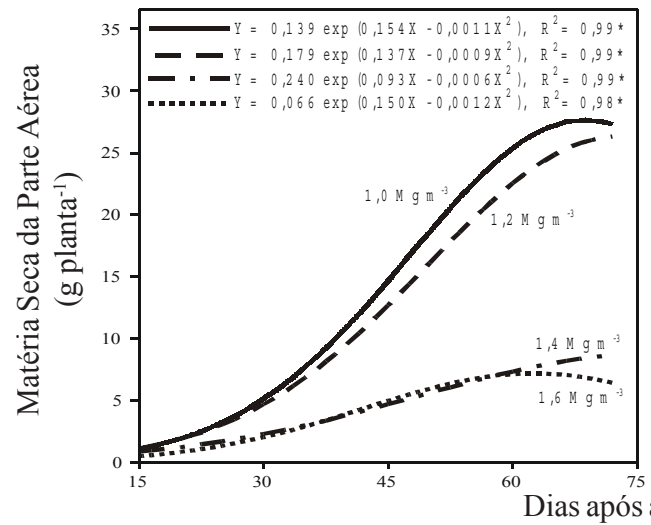

B.

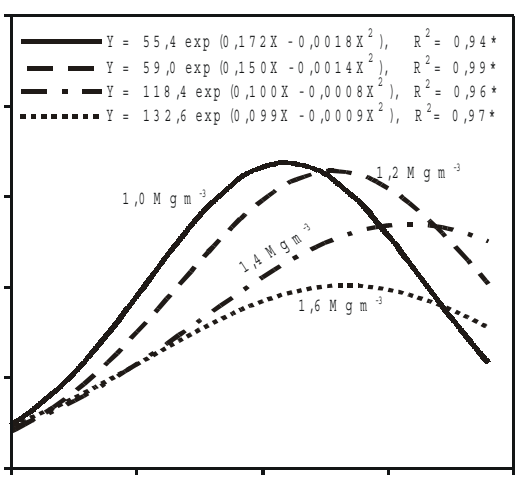

D.

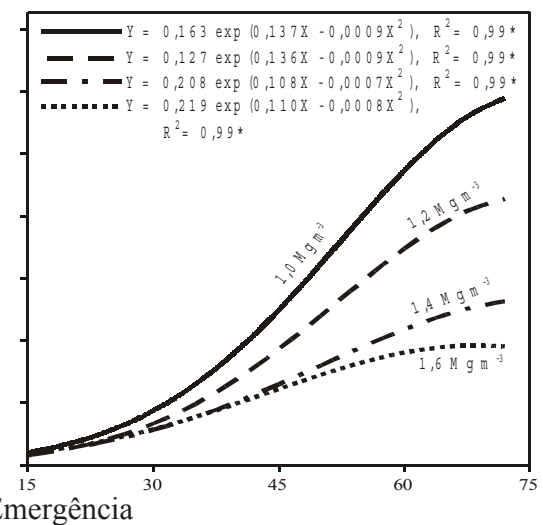

Figura 4. Área foliar e massa da matéria seca da parte aérea das cultivares Pérola (A, C) e BAT 477 (B, D) submetidas a quatro níveis de densidade do solo, na camada superficial 
(1992). Merotto Jr. \& Mundstock (1999) verificaram que o raio das raízes aumentou com a compactação e atribuíram isto ao aumento no tamanho e no número de células do córtex. $\mathrm{Na}$ camada de 20 - $40 \mathrm{~cm}$, o comportamento da espessura radicular foi semelhante nas densidades de 1,0 e $1,2 \mathrm{Mg} \mathrm{m}^{-3}$ (Figs. 3C e 3D).

A área foliar e a massa de matéria seca da parte aérea por planta, de ambas as cultivares, decresceram com o aumento da densidade do solo (Fig. 4). De maneira semelhante ao verificado com a massa da matéria seca e com a densidade de comprimento radicular, a redução nessas variáveis da parte aérea foi mais acentuada quando a densidade aumentou para valores maiores que 1,2 $\mathrm{Mg} \mathrm{m}^{-3}$. As reduções foram mais expressivas para a cultivar Pérola. Merotto Jr. \& Mundstock (1999) também verificaram redução na massa da matéria seca da parte aérea, com a compactação do solo.

A massa específica foliar da cultivar Pérola aumentou com o incremento da compactação do solo (Fig. 5A). Este efeito não foi tão expressivo na cultivar BAT 477 (Fig. 5B) indicando que o estresse físico, provocado pelos diferentes níveis de densidade do solo, influenciou diferentemente a translocação de carboidratos nas duas cultivares. A cultivar Pérola, provavelmente por haver apresentado maior aumento da massa

A.

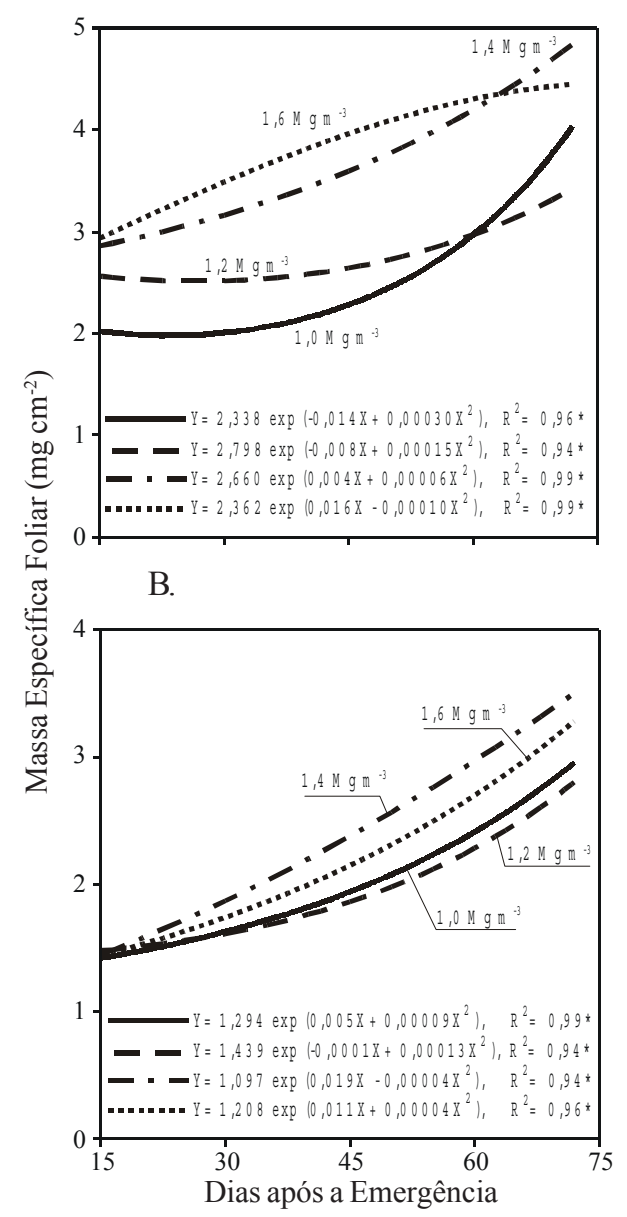

Figura 5. Massa específica foliar das cultivares Pérola $(A, C)$ e BAT 477 (B, D) submetidas a quatro níveis de densidade do solo, na camada superficial específica foliar, ou seja, acúmulo de carboidratos na folha, teve a translocação de carboidratos mais severamente afetada por fatores associados à compactação do solo. Hakansson et al. (1988) sugerem que a redução do crescimento do dossel e da produtividade em solos compactados se deve também à menor absorção de nutrientes e água. Neste trabalho, o teor de água do solo foi monitorado para manter a planta em boas condições hídricas; entretanto, as restrições ao desenvolvimento radicular podem ter afetado a absorção de nutrientes, devido ao menor volume de solo explorado pelas raízes. Apenas nas densidades de 1,0 e 1,2 $\mathrm{Mg} \mathrm{m}^{-3}$, as raízes conseguiram ultrapassar a camada compactada.

A densidade de comprimento radicular relacionou-se linearmente com os parâmetros que avaliaram o comportamento da parte aérea, massa da matéria seca e área foliar (Figura 6) sendo o comportamento das cultivares muito semelhante. Considerando-se que os níveis de compactação do solo afetaram diferentemente as cultivares, tanto em relação à parte aérea como à radicular, isto sugere que outros fatores, além da simples relação parte aérea:sistema radicular, influenciam o comportamento diferencial das cultivares à ação da densidade do solo; talvez fitohormônios produzidos pelo sistema radicular, em resposta ao estresse físico provocado à planta pela compactação do solo. Andrade et al. (1993) também chegaram a hipóteses semelhantes, pois as plantas sob estresse físico provocado pela compactação apresentaram menor crescimento o qual, por sua vez, não foi influenciado pelo suprimento de água, de oxigênio nem de nutrientes, e muito menos pela disponibilidade de carboidratos.

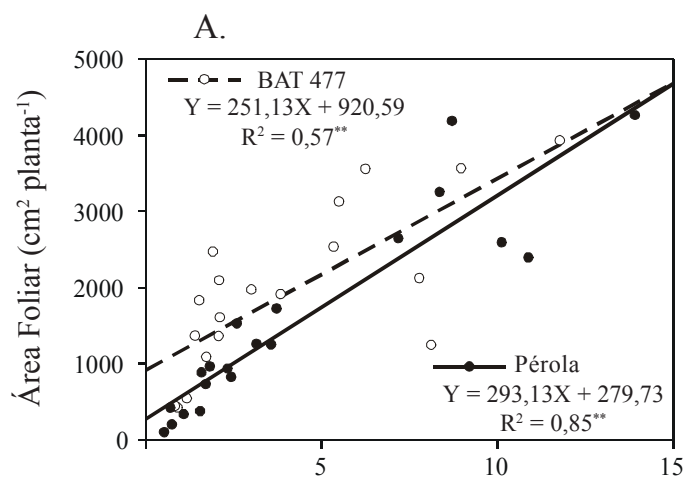

B.

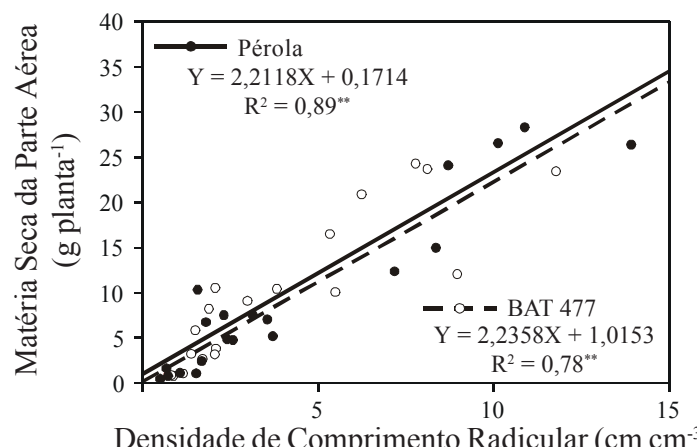

Figura 6. Área foliar (A) e massa da matéria seca da parte aérea (B) em função da densidade de comprimento radicular presente na camada de $0-20 \mathrm{~cm}$ 


\section{CONCLUSÕES}

1. O aumento da compactação do solo afetou negativamente o desenvolvimento do sistema radicular e da parte aérea do feijoeiro, cujo efeito foi mais expressivo a partir da densidade do solo de $1,2 \mathrm{Mg} \mathrm{m}^{-3}$.

2. A cultivar Pérola apresentou as partes aérea e radicular mais desenvolvidas que a BAT 477, quando não havia impedimento físico no solo ao desenvolvimento radicular.

3. A cultivar BAT 477 caracterizou-se pela rusticidade, pois foi menos afetada que a Pérola, quando submetida à compactação do solo.

\section{LITERATURA CITADA}

Andrade, A.; Wolfe, D.W.; Fereres, E. Leaf expansion, photosynthesis and water relations of sunflower plants grown on compacted soil. Plant and Soil, Dordrecht, v.149, p.175-184, 1993.

Barton, H.; McCully, W.G.; Taylor, H.M.; Box, J.E.J. Influence of soil compaction on emergence and first-year growth of seeded grasses. Journal of Range Management, Denver, v.19, p.118-121, 1966.

Beemster, G.T.S.; Masle, J; Williamson, R.E.; Farquhar, G. Effects of soil resistance to root penetration on leaf expansion in wheat (Triticum aestivum L.): Kinematic analysis of leaf elongation. Journal of Experimental Botany, London, v.47, p.1663-1678, 1996.

Cintra, F.L.D.; Mielniczuk, J.; Scopel, I. Caracterização do impedimento mecânico em um Latossolo Roxo do Rio Grande do Sul. Revista Brasileira de Ciência do Solo, Campinas, v.7, p.323-327, 1983.

EMBRAPA - Empresa Brasileira de Pesquisa Agropecuária. Centro Nacional de Pesquisa de Solos (Rio de Janeiro, RJ). Manual de métodos de análise de solos. 2.ed. Rio de Janeiro: EMBRAPA-CNPS, 1997. 212p. EMBRAPA-CNPS. Documentos, 1

Fernandez, E.M.; Crusciol, C.A.C.; Thimoteo, C.M. de S.; Rosolem, C.A. Matéria seca e nutrição da soja em razão da compactação do solo e adubação fosfatada. Científica, São Paulo, v.23, n.1, p.117-132, 1995.
Guimarães, C.M.; Moreira, J.A. Compactação do solo na cultura do arroz de terras altas. Pesquisa Agropecuária Brasileira, Brasília, v.36, n.4, p.703-707, 2001.

Hakansson, I.; Voorhees, W.B.; Riley, H. Vehicle and wheel factors influencing soil compaction and crop response in different traffic regimes. Soil \& Tillage Research, Amsterdam, v.11, p.239-282, 1988.

Meredith, H.L.; Patrick Jr., W.H. Effects of soil compaction on subsoil root penetration and physical properties of three soils in Louisiana. Agronomy Journal, Madison, v.53, p.163-167, 1961.

Merotto Jr., A.; Mundstock, C.M. Wheat root growth as affected by soil strength. Revista Brasileira de Ciência do Solo, Viçosa, v.23, n.2, 197-202, 1999.

Newman, E.L. A method of estimating the total length of root in a sample. Journal of Applied Ecology, Oxford, v.3, p.139-145, 1966.

Orzolek, M.D. Establishment of vegetables in the field. Hort Technology, Alexandria, v.1, p.78-81, 1991.

Oussible, M.; Crookston, R.K.; Larson, W.E. Subsurface compaction reduces the root and shoot growth and grain yield of wheat. Agronomy Journal, Madison, v.84, p.34-38, 1992.

Rosolem, C.A.; Almeida. A.C. da S.; Sacramento, L.V.S. do. Sistema radicular e nutrição da soja em função da compactação do solo. Bragantia, Campinas, v.53, n.2, p.259-266, 1994.

Rosolem, C.A.; Fernandez, E.M.; Andreotti, M.; Crusciol, C.A.C. Crescimento radicular de plântulas de milho afetado pela resistência do solo à penetração. Pesquisa Agropecuária Brasileira, Brasília, v.34, n.5, p.821-828, 1999.

Stone, L.F.; Guimarães, C.M.; Moreira, J.A.A. Compactação do solo na cultura do feijoeiro (Phaseolus vulgaris 1.): I. Efeito nas propriedades físico-hídricas do solo. Revista Brasileira de Engenharia Agrícola e Ambiental, Campina Grande, v.6, n.2, p. 207-212, 2002.

Taylor, H.M. Methods of studying root systems in the field. HortScience, Alexandria, v.21, n.4, p.952-956, 1986.

Veen B.W. The influence of mechanical impedance on the growth of maize roots. Plant and Soil, Dordrecht, v.66, p.101-109, 1982. 